\title{
Effect of Anise (Pimpinella Anisum L.) as Phytoestrogen on Some Sex Hormones and Biochemical Parameters
}

\author{
Eman G.E. Helal ${ }^{1}$, Mohamed A. Abd-El-Aziz ${ }^{2}$, Shaimaa S. Ahmed ${ }^{1}$ \\ Zoology Department, Faculty of Science, Al-Azhar University (Girls), Cairo, Egypt. ${ }^{1}$ \\ Physiology Department, Faculty of Medicine, Al-Azhar University (Boys), Cairo, Egypt ${ }^{2}$ \\ *Corresponding Author: Eman G.E. Helal, E-mail: emanhelal@ hotmail.com, mobile: 00201001025364, Orchid.org/0000- \\ 0003-0527-7028.
}

\begin{abstract}
Background: Phytoestrogen is a plant derived compound which have estrogenic effect similar to estrogen.

Aim of work: The present study was carried out to investigate some pharmacological and biochemical effects of anise oil on male albino rats. Materials and methods: twelve animals were divided randomly into two groups. Group A: Control. Group B: treated rats. The treated rats were given an oral dose of $1 \mathrm{ml} / \mathrm{kg}$ body weight/day anise oil once daily for one month. At the end of the experiment, blood samples were collected for biochemical analysis. Results: The anise oil induced highly significant decrease $(\mathrm{p}<0.01)$ in TC, TG, LDL, VLDL, LDL/HDL. In addition, significant increase $(\mathrm{p}<0.05)$ in HDL and highly significantly decreased in FSH, LH, testosterone and sperm count compared to normal control group. Conclusion: This study showed that high levels of anise intake cause hormonal disturbance and decrease sperm count.
\end{abstract}

Keywords: Anise oil, Lipid profile, Albino rats, sperm count, Physiological parameters.

\section{INTRODUCTION}

Anise (Pimpinellaanisum $\mathbf{L}$.) is a flowering plant in the Apiaceae family, also called aniseed ${ }^{(\mathbf{1})}$. Anise is a natural herbal plant that grows widely in Egypt and many Arab countries. Anise is commonly used in human nutrition to regulate the balance of physical and sexual hormones. It contains essential oils and fatty acids.The main component of essential oils is anetholthat biologically inhibits bacteria (2) and stimulates the secretion of gastrointestinal enzyme and appetite ${ }^{(3)}$. The taste and smell of anise are mainly due to the essential oil, which is $80-90 \%$ trans-anethole, with other components consisting of cis-anethole, safrole, estragole, p-anisaldehyde, anisketone,linalool and $b$-farnesene ${ }^{(4)}$.

The seeds of anise contain 1.5-6\% essential oil, 10$20 \%$ fixed oil and $18 \%$ protein. The main constituents of the essential oil are $90 \%$ anethole, 2-4\% gammahimachalene, $<1 \%$ p-anisaldehyde, $0.9-1.5 \%$ methylchavicol, 3\% cis-pseudoisoeugenyl 2methylbutyrate and $1.3 \%$ trans-pseudoisoeugenyl2methylbutyrate ${ }^{(5)}$. The main constituent of the anise oil anethole, has been considered as the active estrogenic agent. Anethole causes premature larche, which is a common disorder characterized by breast development, usually younger than 2 years, with no other signs of puberty. It is usually associated with adrenal or ovarian disorders and hypothyroidism ${ }^{(6)}$.

Anise has also been shown to have anticancer ${ }^{(7)}$, antioxidative, antihemolytic, anti-inflammatory ${ }^{(8)}$, antihyperglycemic and hypolipidemic ${ }^{(9)}$.

\section{MATERIALS AND METHODS}

Anise oil extracts were purchased from Cap Pharm for Extracting Natural Oils and Herbs, Cairo, Egypt.

\section{Experimental animal}

The experiment was carried out on 12 male albino rats of Rattus rattus strain weighting (130-140gm) obtained from animal farm of El-Nile Company for Pharmaceutical Products (Cairo, Egypt). Animalswere housed in metallic cages and maintained under standard condition of temperature, humidity and naturallight/dark cycle along the experimental period. Food and water were available throughout the experiment ad libitum. Rats were left to acclimatize for one week before starting the experiment.

Experimental design

In current study, 12 male albino rats were divided into two equal groups (6 rats in each group) as the following:

Group I: (control group) comprised of normal rats and maintainedon standard pellet diet and tap water $a d$ libitum for 30 days.

Group II: rats received orally anise oil $(1 \mathrm{ml} / \mathrm{kg}$ body weight) for 30 days.

Body weight measurement

Body weight was recorded before and at the end of the experiment.

\section{Blood samples collection}

At the end of the experimental period, the blood samples were collected from the retero-orbital sinus after overnight fasting and rats being anesthetized by ether. Serum was separated by centrifugation at $2500 \mathrm{~g}$ for 15 minutes at room temperature to estimate biochemical parameters.

\section{Biochemical analysis}

Assessment of biochemical parameters:

In the present study total protein (TP) and albumin concentration were estimated, then serum globulin 
concentrations were calculated according to the formula: Globulin $(\mathrm{g} / \mathrm{dl})=$ total protein $(\mathrm{g} / \mathrm{dl})-$ albumin (g/dl).

Aspartate aminotransferase (ASAT), alanine aminotransferase (ALAT) activities, fasting blood glucose concentration, creatinine, BUN concentrations as well as lipid profile including total cholesterol, triglycerides and high-density lipoprotein cholesterol (HDL-C) were also determined. All parameters were estimated using Bio Merieux SA kits, France.

The ratio of serum albumin/ globulin was determined. However, ratios of TC/HDL (risk factor 1) and LDL/HDL (risk factor 2) were also calculated after calculation of serum LDL-C (low-density lipoprotein cholesterol) and VLDL (very low density lipoprotein cholesterol) using the Friedewald' $\mathbf{s}^{(10)}$ and Norbert ${ }^{(11)}$ formulas, respectively as following:

Friedewald's equation:

$\mathrm{LDL}(\mathrm{mg} / \mathrm{dl})=\mathrm{TC}-\{\mathrm{HDL}+[\mathrm{TG} / 5]\}$.

Norbert equation: $\mathrm{VLDL}=\mathrm{TG} / 5$.

TC/HDL (risk factor 1).

LDL/HDL (risk factor 2).

Hormonal assay

Estimation of serum luteinizing hormone (LH), follicles-stimulating hormone (FSH) and testosterone (T) levels were determine using manufacture instructions of kit. All kits used for hormone assay were obtained from Monobind Inc. lake forest CA 92630, USA.

\section{Sperm collection and evaluation}

The rats were scarified and left caudal epididymis was separated and the total recovered sperm during $4 \mathrm{~h}$ of incubation in normal saline (volume $=1 \mathrm{ml}, 35 \sim 37^{\circ} \mathrm{C}$ ) was calculated. The sperm concentration was determined by the conventional method using a hemocytometer chamber for the red blood cell count. The right epididymis was finely minced by anatomical scissors in $1 \mathrm{ml}$ of warmed isotonic saline in a petri dish. The sperm progressive motility (SPM) was estimated by evaluating 4 fields of asperm droplet under a cover-slip on a warm glass slide $\left(35 \sim 37^{\circ} \mathrm{C}\right)$ under light microscopy $(\times 40)$. The sperm vitality was assayed using a conventional procedure of eosin Bnigrosin stain $(1.67 \%$ eosin, $10 \%$ nigrosin, and $0.1 \mathrm{M}$ sodium citrate) under $\times 100$ magnification and 100 sperm were counted. All of the sperm evaluation procedures were carried out based on the World Health Organization manual for human sperm analysis with some modifications ${ }^{(12)}$.

\section{Ethical approval}

The study was approved by the Ethics Board of AlAzhar University.

\section{Statistical analysis}

The results were expressed as mean \pm SEM. Data were analyzed by t-test and were performed using the Statistical Package (SPSS) program, version 19.

\section{RESULT}

\section{Body weight and glucose level}

Results of the present study showed a significant increase $(\mathrm{P}<0.001)$ inpercentage of change of body weight gain and in glucose level in the treated groups when compared with control rats (Table 1).

Table (1): \%change of body weight and FBS levels in the control and treated groups.

\begin{tabular}{|l|l|c|}
\hline $\begin{array}{l}\text { Groups } \\
\text { Parameters }\end{array}$ & Control & Anise oil \\
\hline $\begin{array}{l}\text { Body weight } \\
\% \text { of change }\end{array}$ & $137.6 \pm 0.4$ & $180.8 \pm 0.4^{*}$ \\
\hline $\begin{array}{l}\text { FBS (mg/dl) } \\
\% \text { of change }\end{array}$ & $94 \pm 2.8$ & $\mathbf{7 0 . 0 2}$ \\
\hline
\end{tabular}

Values represent mean $\pm \mathrm{SE}$ (standard error). ( $\mathrm{p}^{*}<0.05$ as compared to control group).

\section{Protein profile}

The present study showed that administration of anise oil to normal rats showed non-significant change in total protein, albumin, globulin and albumin globulin ratio in the treated groups when compared to the control animals (Table 2).

Table (2): Changes in the total protein, albumin, globulin and albumin/globulin levels in the control and treated group.

\begin{tabular}{|c|c|c|}
\hline Groups Parameters & Control & Anise oil \\
\hline $\begin{array}{c}\text { Total protein }(\mathrm{g} / \mathrm{dl}) \\
\text { \% of change }\end{array}$ & $6.4 \pm 0.12$ & $\mathbf{6 . 1 \pm 0 . 0 9}$ \\
\hline $\begin{array}{c}\text { Albumin }(\mathrm{g} / \mathrm{dl}) \\
\text { \% of change }\end{array}$ & $3.7 \pm 0.11$ & $\mathbf{4 . 6 \%}$ \\
\hline Globulin $(\mathrm{g} / \mathrm{dl})$ & & $-13.5 \%$ \\
\% of change & $2.7 \pm 0.10$ & $2.9 \pm 0.09$ \\
Albumin/Globulin(g/dl) & & $7.4 \%$ \\
\hline of change & $1.3 \pm 0.1$ & $1.1 \pm 0.06$ \\
\hline
\end{tabular}

Values represent mean \pm SE (standard error). 


\section{Kidney function}

Results of the present study showed non-significant change in urea and creatinine in the treated groups when compared to control animals (Table 3).

Table (3): Changes in the BUN and creatinine levels in the control and treated group

\begin{tabular}{|c|c|c|}
\hline Groups & Control & Anise oil \\
\hline BUN (mg/dl) & & $19 \pm 0.4$ \\
\% of change & $20.3 \pm 0.2$ & $-6.4 \%$ \\
\hline Creatinine (mg/dl) & & $0.6 \pm 0.01$ \\
\% of change & $0.7 \pm 0.2$ & $-14.2 \%$ \\
\hline
\end{tabular}

Values represent mean \pm SE (standard error).

\section{Liver functions}

Results of the present study showed non-significant change in ALAT and ASAT in the treated groups when compared to control rats (Table 4).

Table (4): Changes in ALAT and ASAT in the control and anise oil group

\begin{tabular}{|l|c|c|}
\hline Groups & Control & Anise oil \\
\hline ALAT(U/L) & & \\
\% of change & $22.5 \pm 0.6$ & $-7.1 \%$ \\
\hline ASAT(U/L) & & $32.9 \pm 0.5$ \\
\% of change & $33.5 \pm 0.5$ & $-1.7 \%$ \\
\hline
\end{tabular}

Values represent mean \pm SE (standard error).

\section{Lipid profile}

A highly significant decrease $(\mathrm{p}<0.01)$ in TC, TG, LDL, LDL/ HDL and highly significant increase in HDL was recorded in treatedgroup as compared to control group (Table 5).

Table (5): Changes in the lipid profile in the control and anise oil group

\begin{tabular}{|l|c|c|}
\hline Groups & Control & Anise oil \\
\hline TC(mg/dl) & & \\
\% of change & $141.3 \pm 0.42$ & $86.3 \pm 1.5 * *$ \\
\hline TG(mg/dl) & & $-38.9 \%$ \\
\hline HD of change & $71.5 \pm 1.56$ & $56.8 \pm 4.44 * *$ \\
\% of change & & $-20.5 \%$ \\
\hline LDL(mg/dl) & $50.33 \pm 0.33$ & $61.33 \pm 0.33 * *$ \\
\% of change & & $21.9 \%$ \\
\hline VLDL(mg/dl) & $71.2 \pm 1.27$ & $14.13 \pm 1.12 * *$ \\
\% of change & & $-80.1 \%$ \\
\hline LDL/HDL(mg/dl) & & $11.03 \pm 0.90 * *$ \\
\% of change & $14.30 \pm 0.31$ & $-22.8 \%$ \\
\hline TC/HDL(mg/dl) & & $\mathbf{0 . 2 2} \pm 0.17 *$ \\
\% of change & $1.22 \pm 0.007$ & $1.40 \pm 0.22$ \\
\hline
\end{tabular}

Values represent mean $\pm \mathrm{SE}$ (standard error). ( $\mathrm{P}^{*}<0.05, \mathrm{p}^{* *}<0.01$ as compared to control group).

\section{Hormones}

The data in table (6) showed a highly significant decreased $(\mathrm{p}<0.01)$ in FSH, LH and $\mathrm{T}$ in anise group when compared to control rats. 
Table (6): Changes in the FSH, LH and testosterone levels in the control and anise oil groups

\begin{tabular}{|c|c|c|}
\hline Groups Parameters & Control & Anise oil \\
\hline FSH(ng/ml) & $2.9 \pm 0.1$ & $1.5 \pm 0.1 * *$ \\
\% of change & & -48.2 \\
\hline LH(ng/ml) & $1.9 \pm 0.1$ & $1.4 \pm 0.1 * *$ \\
\% of change & & $-26.3 \%$ \\
\hline Testosterone $(\mu \mathrm{u} / \mathrm{dl})$ & $3.9 \pm 0.2$ & $\mathbf{2 . 5 \pm 0 . 2 * *}$ \\
\% of change & & $-35.8 \%$ \\
\hline
\end{tabular}

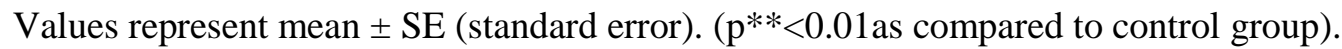

Sperm count

The data in table (7) showed decrease in sperm count in anise oil group when compared to control rats.

Table (7): Sperm count in the control and anise oil group.

\begin{tabular}{|c|c|c|}
\hline Groups Parameters & Control & Anise oil \\
\hline $\begin{array}{c}\text { Sperm count*10\%/ml } \\
\% \text { of change }\end{array}$ & $100 \pm 0.01$ & $36 \pm 0.01$ \\
\end{tabular}

\section{DISCUSSION}

Body weight and glucose level

The current study revealed that anise oil led to an increase in body weight.It has been mentioned that anise oil has a positive effect on the digestion of food. This effect may be attributed to the active compounds of anisesuch as anethole, eugenol, anisaldehyde, estragol and methylchavicol, which have a special tonic effect on the digestive system. Anethole is the main compound in pathogenic microorganisms in the gastrointestinal tract where it showed an increasing effect on weight gain and feed conversion ${ }^{(13)}$.

In the present study,the administration of anise oil reduced serum level of glucose. Thisresult indicates that anise have anti diabetic effect ${ }^{(14)}$. This is supported by significant decrease of lipid peroxidation (a marker of oxidative stress in erythrocytes and plasma).

Decreased glucose levels indicate control over oxidative stress as hyperglycemia can directly cause increased generation of reactive oxygen species as glucose undergoes autooxidation and generate $\mathrm{OH}$ radicals ${ }^{(15)}$. In addition, glucose reacts with proteins in a non-enzymatic manner leading to the development of amadori products followed by formation of Advanced Glycation Endproducts AGEs ${ }^{(16)}$.

In the present study, anise oil led to decrease in the level of cholesterol, triglycerides and LDL-c levels. The polyphenols present in the anise oil could donate electrons and react with free radicals to convert them into the stable products and terminate the free radical chain whereas other compounds in the oil act as chainbreaking agents in lipid peroxidation ${ }^{(17)}$.

Antioxidant properties and radical scavenging activity is the mechanism by which the anise oil ameliorated cholesterol, triglyceride and LDL-c.So, anise suggested to be a co-method for clinical management of hyperlipidemic patients ${ }^{(18)}$.

In the present study, anise oil led to decrease in the level of FSH, LH, and testosterone. The androgens, as paracrine hormones, are required by the Sertoli cells in order to support sperm production (spermatogenesis).

The regulation of spermatogenesis by FSH and testosterone is occurring by the action of these hormones on Sertoli cell ${ }^{(19)}$.

Phytoestrogens is an estrogenic agent, directly or indirectly interfering with the physiological effect of estrogens and interfere with the function of male reproductive system ${ }^{(20)}$.

The main constituent of the anise oil anethole, has been considered as the active estrogenic agent.Anise oil also contain safrol, which lowers the level of androgen and leads to hormonal disturbance and decrease sperm count ${ }^{(21)}$.Furthermore, it has been suggested ${ }^{(22)}$ that estrogen exposure interfereswiththe androgen receptor pathway and affect the late steps of spermatogenesis.According to the traditional thinking, drinking anise by boys may be harmful to their reproductive system.

Tyler and Foster ${ }^{(23)}$ found that safrol is toxic in a concentration of $1 \%$ of the diet, producing weight loss, testicular atrophy, bone marrow depletion and also produces tumors in two-thirds of the animals treated with it.

\section{CONCLUSION}

This study showed that high levels of anise intake cause hormonal disturbance and decrease sperm count. 


\section{REFERENCES}

1. Thomas S B(1878):Editor-in-chief, with William Robertson Smith. Anise", Encyclopædia Britannica, 9th ed., Vol. II, New York: Charles Scribner's Sons,pp: 5758.

2. Sagdic, O,Ozcan M (2003): Antibacterial activity of Turkish Spice hydrosols. Food Control, 14: 141-143.

3. Albert B (1980): Fennel and anise estrogenic agent. Ethnopharmacology, 2: 337-344.

4. Ishikawa T, Fujimatu E,Kitajima J (2002): WaterSoluble Constituents of Anise: New Glucosides of AnetholeGlycol and Its Related Compounds. Chemical \& Pharmaceutical Bulletin, 50(11): 1460-1466.

5. Rodrigues V M, Rosa PT,MeirelesM A,Marques A JPetenate (2003): Supercritical extraction of essential oil from aniseed (Pimpinellaanisum L.) using $\mathrm{CO}_{2}$ : solubility, kinetics and composition data. J Agric Food Chem., 51(6): 1518-1523.

6. Türkyilmaz Z, Karabulut R, Sönmez K,Can BaşaklarA(2008): A striking and frequent cause of premature the larche in children: foeniculumvulgare. $\mathbf{J}$ Pediatr Surg., 43(11): 2109-2111.

7. Kadan S, Rayan M,Rayan A(2013): Anticancer activity of anise (PimpinellaanisumL.) seed extract. The Open Nutraceuticals J., 6:1-5.

8. Iyer SR, Ullagaddi RC,BondadaA(2013): Antihemolytic and anti-inflammatory activities of aniseed (Pimpinellaanisum L.). Journal of Advance Pharmaceutical Research and Bioscience,1(2):52-59.

9. Rajeshwari U, Shobha I,Andallu B (2011): Comparison of aniseeds and coriander seeds for antidiabetic, hypolipidemic and antioxidant activities. Spatula DD Peer Reviewed Journal on Complementary Medicine and Drug Discovery, 1(1):9-16.

10. Friedwald's WT, Levy RI,Fredrickson DS et al. (1999): Estimation of the concentration of low-density lipoprotein cholesterol in plasma, without use of the preparative ultracentrifuge. Clin. Chem., 18:499-502.

11. Norbert WT (1995): clinical guide to laboratory tested. $3^{\text {rd }}$ ed.saunders W.B.,company ,philadephi.
12. WHO (2010): WHO laboratory manual for the examination and processing of human semen. 5th ed. Geneva, Swittzerland: WHO press.

13. Çabuk M, Alçiçek A, Bozkurt M,Imre N (2003): Antimicrobial properties of the essential oils isolated from aromatic plants and using possibility as alternative feed additives II. South African Journal of Animal Science 33 (2): 89-94.

14. Rajeshwari U, Shobha I,Andallu B (2011): Comparison of aniseeds and coriander seeds for antidiabetic, hypolipidemic and antioxidant activities. Spatula DD, 1(1): 9-16.

15. Turko IV, Marcondes S, Murad F (2001): Diabetesassociated nitration of tyrosine and inactivation of tyrosine and inactivation of succinyl-CoA: 3-oxo acid CoA-transferase. Am. J. Physiol. Heart. Circ. Physiol., 281 (6): 2289-2294

16.Johansen JS, Harris AK, Rychly DJ, Adviye E (2005): Oxidative stress and and the use of antioxidants in diabetes: linking basic science to clinical practice. Cardiovascular Diabetol., 4 (5): 1475-2840.

17. Shimaa M H A (2015): Effect of Some Levels of Cardamom, Clove and Anise on Hepatotoxicity in Rats Caused by CCL4. World App Sci J., 33 (6): 854-865.

18. Shobha RI and Andallu B (2018): Antioxidant, AntiDiabetic and Hypolipidemic Effects of Aniseeds (Pimpinellaanisum L.): In vitroand in vivo Studies. J Complement Med Alt Healthcare, 5 (2): 1-11.

19. Griswold MD (1998): The central role of Sertoli cells in spermatogenesis. Cell and Developmental Biology, 9:411-416.

20.Giwercman A (2011): Estrogens and phytoestrogens in male infertility. Current Opinion in Urology, 21(6): 519526.

21.IbrahimA A (2008): Correlation between fennel- or anise-oil administration and damage to the testis of adult rats. Egyptian J of Biol., 10: 62-76.

22. Cederroth CR, Auger J, Zimmermann C et al. (2010): Soy, phyto-oestrogens and malereproductive function: a review. Int J Androl., 33:304-316.

23. Tyler VE,Foster $S$ (1999):“A sensible guide to the use of herbs and related remedies" 4thEd. New York, Haworth Herbal Press, pp: 337-339. 